\title{
An audit of transsphenoidal surgery on nonfunctioning pituitary adenomas
}

Authors: Moure L, Larrañaga I, Valle S, González B, González P, Gaztambide S

Cruces University Hospital

\section{OBJECTIVE}

Clinically nonfunctional pituitary adenomas are relatively an uncommon disease. The aim of this work is to describe the clinical characteristics and to review the results of transsphenoidal surgery (TS) of pituitary adenomas in a reference center.

\section{METHODS}

A retrospective study (1995-2014) of 66 patients (50\% men) diagnosed with pituitary adenomas by a magnetic resonance imaging (MRI) was conducted. Demographic, clinical, biochemical data and the results of TS were collected. For statistical processing program SPSS version 22.0 was used.

Basal clinical characteristics ( $=66)$
\begin{tabular}{|l|l|}
\hline Mean age (years) & $57 \pm 16$ '8 \\
\hline Clinical presentations (\%) & $\begin{array}{l}\text { Visual symptoms }(36,4) \\
\text { Incidental pituitary mass }(34,8)\end{array}$ \\
\hline Tumor mean size (mm) & $26,6 \pm 8,8 \mathrm{~mm}$ \\
\hline $\begin{array}{l}\text { Pathological visual field } \\
\text { testing at diagnosis }\end{array}$ & $\begin{array}{l}59 \\
34,8 \% \text { bitemporal hemianopsia }\end{array}$ \\
\hline
\end{tabular}

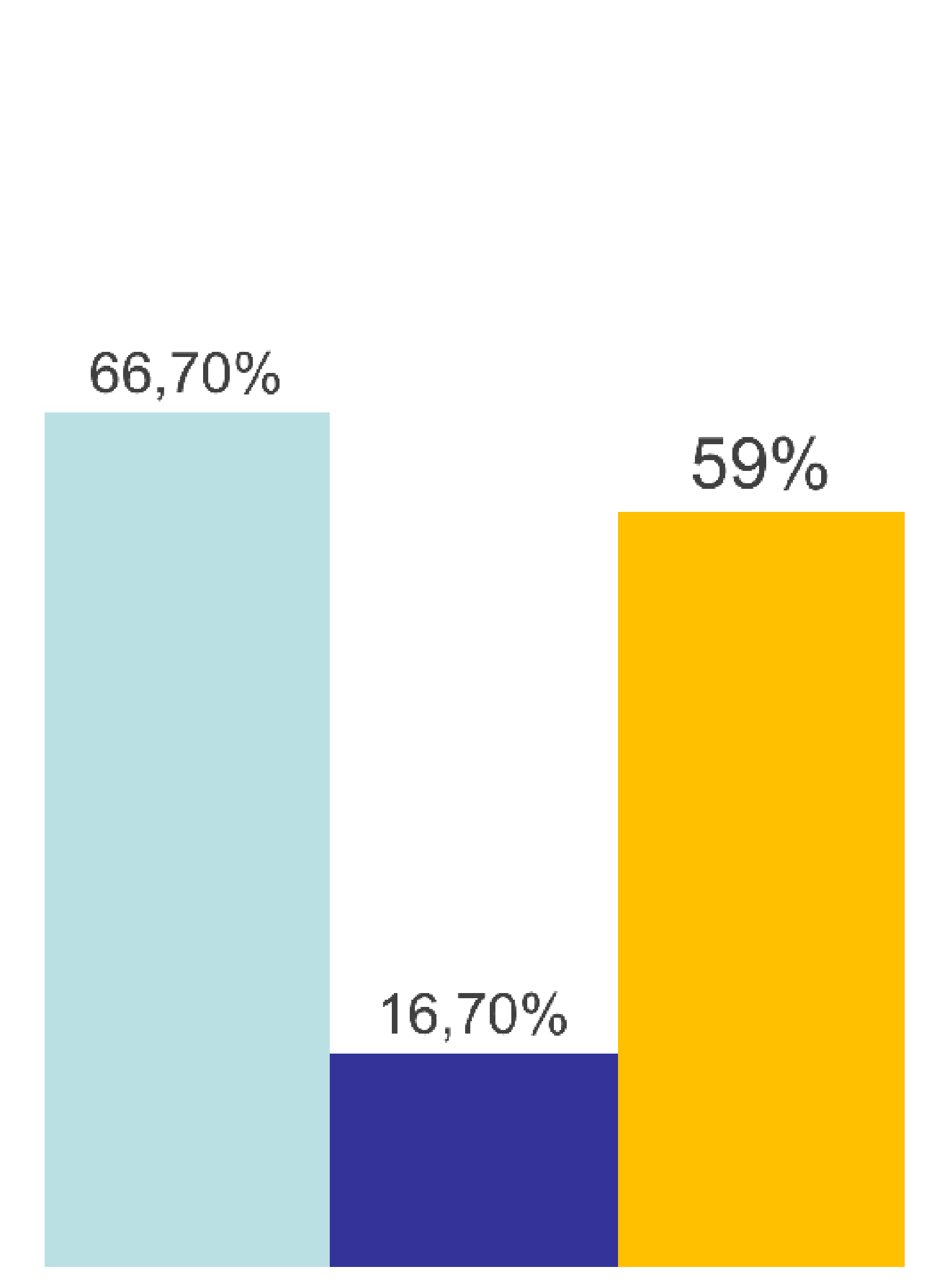

Before surgery

- Any hormone deficiency

- panhypopituitarism
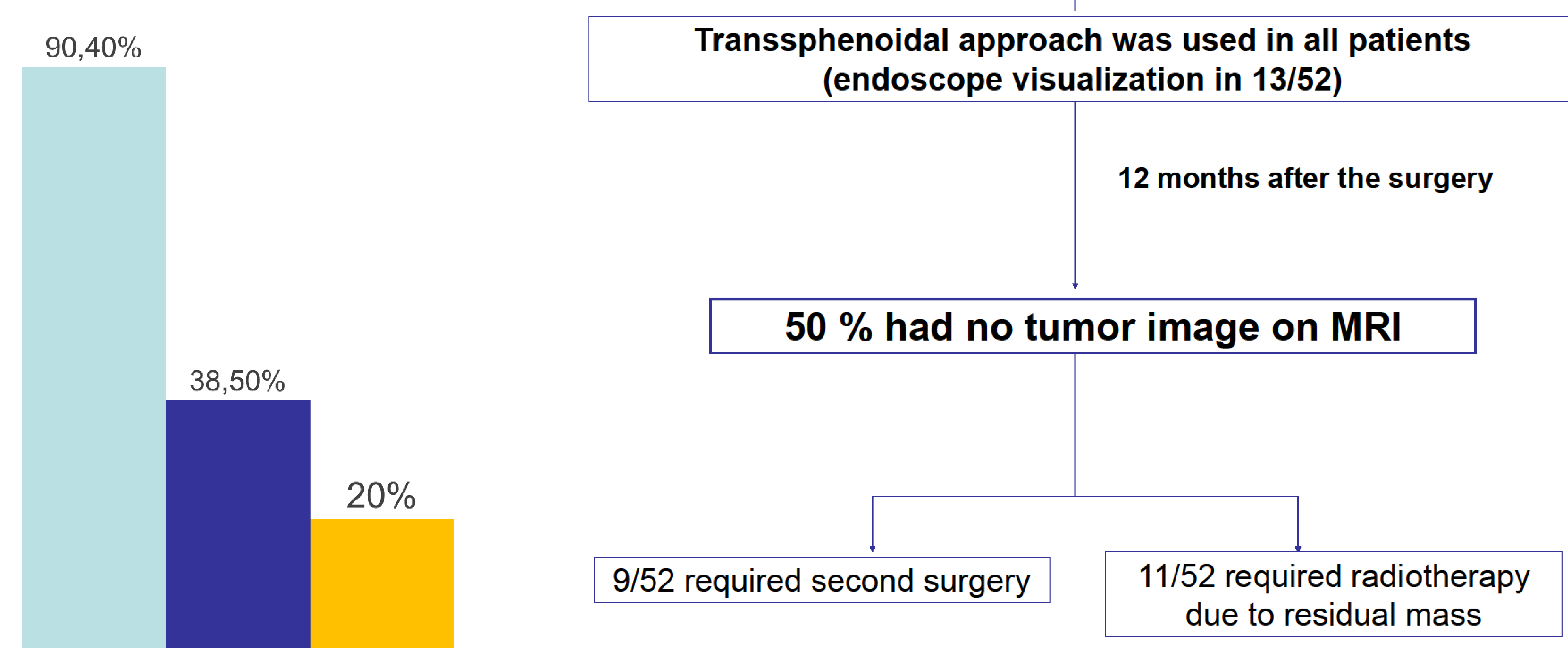
due to residual mass

\section{RESULTS}

